\author{
N.V. Fedorova ${ }^{1}$ and A.V. Baulo ${ }^{2}$ \\ ${ }^{1}$ Arctic Research Center, \\ Respubliki 20, Salekhard, 629008, Russia \\ E-mail:mvk-fedorova@mail.ru \\ ${ }^{2}$ Institute of Archaeology and Ethnography, \\ Siberian Branch, Russian Academy of Sciences, \\ Pr. Akademika Lavrentieva 17, Novosibirsk, 630090, Russia \\ E-mail:bau194@yandex.ru
}

\title{
"Portrait" Medallions from the Kazym Hoard
}

We describe so-called portrait medallions and plaques with similar representations from a hoard found near Kyzym, the Beloyarsky District of the Khanty-Mansi Autonomous Okrug-Yugra in the summer of 2014. We introduce 17 artifacts cast of bronze and differing in shape and technological level. These fall into two groups in terms of quality. The principal questions addressed in the article are where, by whom, and based on which prototypes the Kazym artifacts were made. To resolve them, we analyze similar artifacts, including silver medallions representing a Parthian king and found in northwestern Siberia, and a series of bronze items from various sites in the Surgut and the Lower Ob region. These parallels, like the presence of numerous "Sarmatian" bronze mirrors in the Kazym hoard, point to the period between the late 1st century $B C$ and the 1st or 2nd centuries $A D$. The results suggest that the "portrait" medallions and other bronze plaques depicting anthropomorphic characters are local replicas of imported prototypes. This testifies, firstly, to stable trade links with ancient civilization centers in the beginning of the Christian era, and secondly, to the absorption of certain elements of foreign traditions by the local culture.

Keywords: Medallion, portrait, Siberia, Kazym, hoard, imitation.

\section{Introduction}

In 2014, an amateur survey in the Beloyarsky District of the Khanty-Mansi Autonomous Okrug-Yugra (KhMAOYugra) resulted in the discovery of two accumulations of metal items. Some of these items were set out on-line at the treasure-hunting sites, with short cover letters. Several artifacts from this hoard were described, and a preliminary analysis was made of them (Baulo, 2016; Shulga, Oborin, 2017; Fedorova, 2018).

Finders reported that the items were discovered on a small island at the confluence of the $\mathrm{Ob}$ and the Kazym (right tributary of the $\mathrm{Ob}$ ), on a low ridge covered with coniferous trees and surrounded by a bog and an oxbow lake. The accumulations of artifacts were not associated with any traces of an archaeological site or a contemporary Khanty sanctuary. Hence these artifacts can probably be attributed to intentional deposits that are often referred to in literature as hoards. The two deposits were discovered at a depth of $20-25 \mathrm{~cm}$, about $30 \mathrm{~m}$ from each other.

The first hoard was placed in a wooden container, possibly a wooden bucket (its round bottom, hollowedout from solid wood, was preserved) covered on the inside with birch-bark. The bucket contained about 200 artifacts, including bronze mirrors of the Sarmatian type and cast plaques with various images. Next to the bucket, a set of 34 Early Iron Age bronze items was found, which had been cast in northwestern Siberia: anthropomorphic

\footnotetext{
Archaeology, Ethnology \& Anthropology of Eurasia 47/4 (2019) 85-92 E-mail: Eurasia@archaeology.nsc.ru (C) 2019 Siberian Branch of the Russian Academy of Sciences

(C) 2019 Institute of Archaeology and Ethnography of the Siberian Branch of the Russian Academy of Sciences (c) 2019 N.V. Fedorova, A.V. Baulo
} 
images and masks, a bird-like image, a flat ring bearing two animal images, and arrowheads. The production location of two pick-axes (chekans) from the set cannot be determined. The second hoard had been placed in a burnt ceramic pot. It contained over 30 bronze items, including "Sarmatian" mirrors, round and rectangular buckles, bird-like figurines, and an image of a standing beaver. The age estimates for the found items, both local and imported, suggest that all three groups of artifacts were buried at the same time, and represent a single collection.

The largest category of goods from both hoards is that of the so-called mirrors, or discs, which, according to A.S. Skripkin, have their closest parallels in the archaeological complexes of the Sarmatian cultures in the Southern Urals, or Asian Sarmatia in his definition (1990: 197). B. Nezabitovska-Vishnevska analyzed the mirrors of identical shape from the Gornoknyazevsk hoard (see (Fedorova, Gusev, Podosenova, 2016: 13-33), and argued that such mirrors were widespread over eastern Europe and Asia. According to her, similar products have been reported from the Sargat culture, Sarmatian culture, and even India and Pakistan (Nezabitovska-Vishnevska, 2017: 102). Notably, similar mirrors were collected in the basins of the Kazym, Lyapin, and Severnaya Sosva rivers, and formed a large collection in the Khanty-Mansiysk Museum. The mirrors were transported to the $\mathrm{Ob}$ basin by the Sargat culture's representatives prior to the 4th century AD (Pristupa, Starodumov, Yakovlev, 2002: 10-13). Such a detailed analysis of the attribution of "Sarmatian" mirrors, which are beyond the scope of this paper, is important for understanding the chronological ranges of the Kazym complex and the area of distribution of this rich collection of imported goods over the $\mathrm{Ob}$ region. The proposed age estimates for the mirrors point to the period from the turn of the eras to the 4th century $\mathrm{AD}$; while the areas where the mirrors were found indicate the southern trade route, through which these goods might have been transported to the Kazym basin.

In 2018, one of the present authors published a paper addressing the available information on the hoards of the Early Iron Age and Middle Ages in Western Siberia: their composition, methods of burial, attribution of goods, and dating of collections (Fedorova, 2018). Four groups of hoards were identified, with varying contents and attributions. The Kazym hoard was attributed to group 2 (the Early Iron Age, turn of the eras), together with the Istyatskaya, Suzgun, and Gornoknyazevsk hoards. These can be undoubtedly regarded as real hoards intentionally buried without any association with cult sites. The hoards show special packing and the dominance of imported goods, including those from distant areas. Some of them contained local imitations of imported goods. Obviously, the hoards of group 2 emerged owing to extension of the contacts of the local population to distant regions, which led not only to the accumulation of imported goods, but also to the translation of new ideas into the local culture ready to accept such significant changes (Ibid.).

\section{Description and analysis of the collection}

The collection of the so-called portrait medallions or plaques from the two hoards includes 17 specimens. Plaques 1 (Fig. 1, 1) and 3 (Fig.1,3) were found in a burnt pot, others in a "bucket". All of them were cast bronze items.

1. Plaque $7.2 \mathrm{~cm}$ in diameter (Fig. 1, 1). This bears an image in high relief on the front. The back is plain, the horizontal loop is underfilled. The plaque is edged with a fillet ornamented with pseudo-twisted cord. The obverse shows a head-and-shoulders portrait of a person with a round face, large almond-shaped eyes, a straight, prominent nose, and small mouth. On the neck, there is a sophisticated adornment, probably a torque. The openfronted clothing is decorated with convex rhombuses along the sleeves and neckline. The head is topped with a sophisticated headgear with a diadem (?) bearing adornments hanging to the shoulders: close to the ears, there are relief herring-bone decorations; lower, there are pendants ending with three short strings of beads with large round beads at the ends. Two holes made during casting are to the left and right of the head. Their purpose is unclear; probably, these are hanging-loops to attach the plaque to a garment or something else.

2. Plaque $4.4 \mathrm{~cm}$ in diameter (Fig. 1, 2). This bears an image in high relief on the front. The back is plain. The plaque is round, and has a small hanging-loop on top. The plaque is edged with a fillet ornamented with pseudotwisted cord. The obverse bears head-and-shoulders portrait of a man. The face is round. The eyes are large, prominent, almond-shaped, with round pupils. The nose is straight and prominent; a moustache or nasolabial folds are shown under the nose; the mouth is small. Thick hair simulating curls is topped with a headgear of the headband type. Indistinct adornments, possibly temple pendants, hang to the shoulders. The open-fronted clothing, also indistinct, is decorated with convex rhombuses. The neck is provided with something like a torque.

3. Plaque $6 \mathrm{~cm}$ in diameter (Fig. 1,3). This bears an image in high relief on the front. The back is plain, with a horizontal loop in the upper part. A part of the plaque close to the right shoulder is missing; the area also shows fractures, possibly made during casting. The plaque is edged with a fillet ornamented with pseudo-twisted cord. The obverse bears a head-and-shoulders portrait of a man, with his arms folded on the chest. The face is oval, the curled hair is shown on the forehead, the hair at the sides is plaited, ending with curls, reaching to the shoulders. The eyes are almond-shaped, the pupils are rendered 
with depressions. The nose is straight and broad; the open mouth is considerably large. The torque on the neck is depicted with "pearls". The clothing is open-fronted; at the neckline, it is decorated with two edges, ornamented with round pits, the ends of the sleeve are decorated in the same way.

4. Plaque $5.5 \mathrm{~cm}$ in diameter (Fig. 1, 4). This bears an image in high relief on the front. The back is plain, with a horizontal loop in the upper part. The plaque is edged with a fillet ornamented with pseudo-twisted cord. Several small fragments are missing. The obverse bears a headand-shoulders portrait of a man; the iconography of the portrait is similar to that of the images described above. The ornaments on the garment are also similar. The only difference is that the background around the character is decorated with round punched nodes.

5. Plaque $4.3 \mathrm{~cm}$ in diameter (Fig. 2, 1). This shows areas of metal underfilling. The image is made in high relief on a flat background. The reverse bears a semiround loop with the remains of a woolen cord. The plaque is edged with a fillet ornamented with pseudo-twisted cord. The obverse shows head-and-shoulders portrait of a man. The top part of the image slightly protrudes above the plaque's circle. The curly hair of the character is bound with a band or some headgear. Hanging temple adornments, each in the form of a stem with rounded ends, reach the shoulders. The decoration on the left side is hardly discernible because of a casting defect. The eyes of the character are large, almond-shaped, with convex ovoid pupils. The eyebrow-arches gradually turn into the prominent nose, under which long mustaches are shown. The chin is prominent; possibly the artisan wanted to represent a short curly beard. The neck of the man is decorated with a torque. The clothing is openfronted, edged with "pearls", followed by two lines: the first one consisting of meander-like pattern, the second of "pearls". Ornamentation with "pearls" is also present on the shoulders.

6. Plaque $10.5 \mathrm{~cm}$ in diameter (Fig. 2, 2). The image is made in high relief on a flat background. There is a hanging-hole on top of the plaque. Noteworthy is the unusual and poor decoration of this plaque as compared with the others. The plaque is edged with a fillet decorated with groups of three parallel incisions. A head-andshoulders portrait is in the center of the plaque. It is framed with a plain fillet; the background bears deep round punch-impressions, sometimes penetrating ones. The head of the character is shown with a haircut, possibly imitating curls. There are also plaits reaching the shoulders, the former ending with triple curls or pendants. The face is rounded, the arched eyebrows adjoin the prominent nose. The eyes are large, almond-shaped, with round pupils. The nasolabial folds are shown, the mouth is rendered with an arched depression. The neck decoration is indiscernible. The clothing is shown schematically.
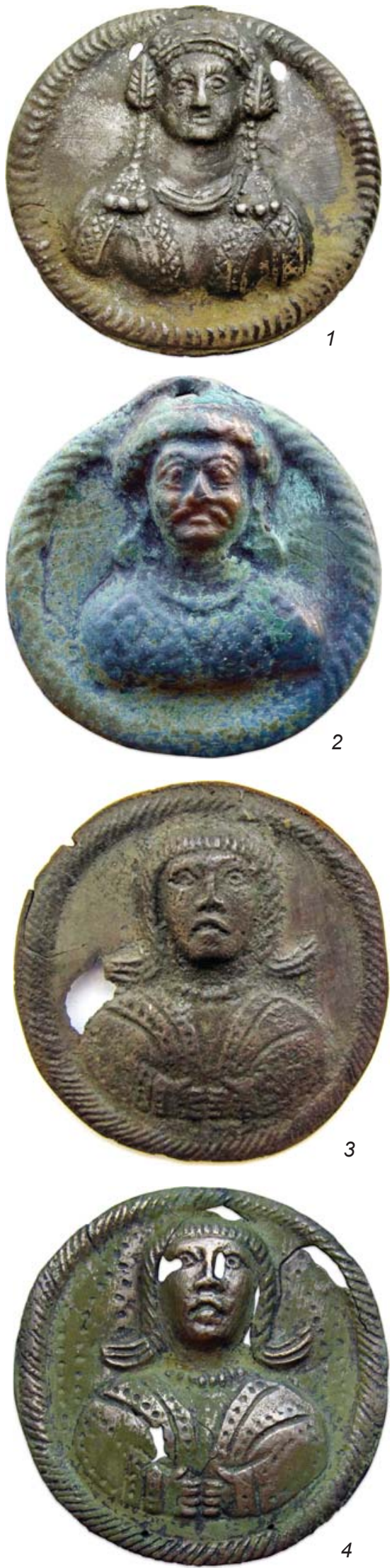

Fig. 1. Bronze round "portrait" medallions. 
It can be seen that the clothing is open-fronted. The shoulders are ornamented with lines of rectangular "pearls"; the same pattern is shown inside the sleeves.

7. Plaque $7 \mathrm{~cm}$ in diameter (Fig. 2,3). The image is made in high relief on the flat background, with scratches of post-casting working. The reverse side is provided with a small hanging loop. The plaque is edged with a fillet in the form of pseudo-twisted cord. The fillet shows a hole
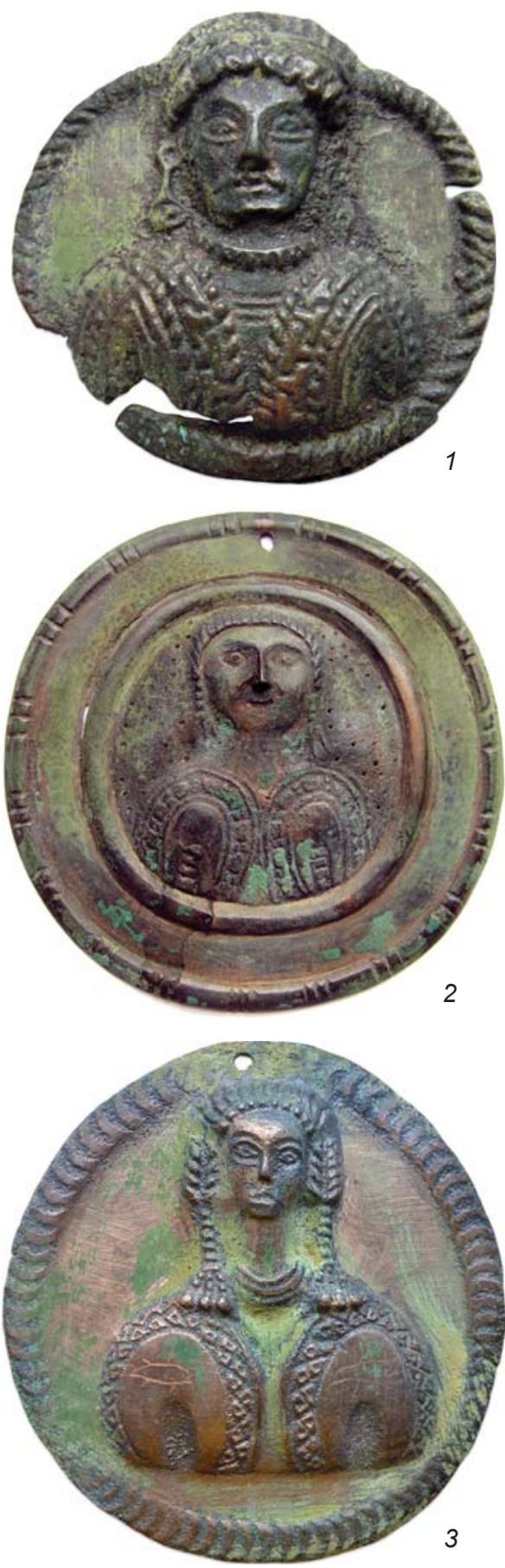

Fig. 2. Bronze round "portrait" medallions. drilled from the reverse. In the center, there is a head-andshoulders portrait of a character.

The head is shown with a haircut imitating curls bound by a band; the plaits end with pendants in the form of three strings of beads hanging to the shoulders.

The face is oval; the eyes are large and almondshaped, with round pupils. The arched eyebrows adjoin the prominent nose; the mouth is indistinct. The neck is long and bears a three-fold torque. The clothing is openfronted, its edges and sleeves are decorated with lines of convex rhombuses with round depressions in the center. The shoulders show later graffiti (a fish and a bird).

8. Plaque $5.7 \times 4.7 \mathrm{~cm}$ in size (Fig. 3). This shows lowquality casting. The plaque's shape follows the outlines of the head-and-shoulders anthropomorphic image, which is atypical for the series under study. The lower edge is uneven and has a hole drilled from the obverse.

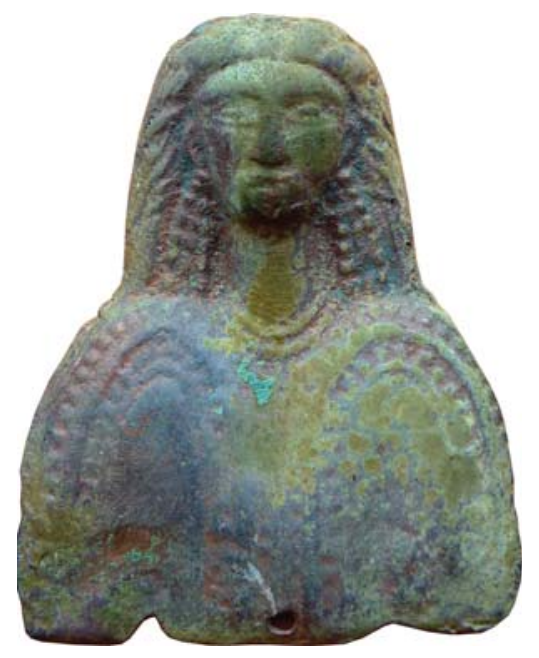

Fig. 3. Plaque in the form of a head-and-shoulders anthropomorphic figure.

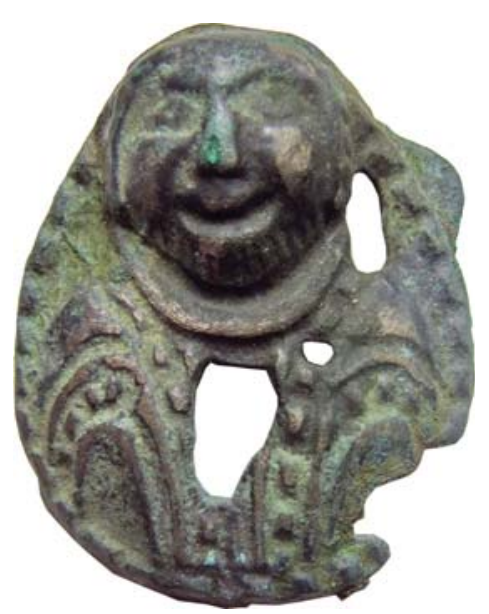

Fig. 4. Plaque with an anthropomorphic half-length figure. 
The reverse shows a small loop with the remains of a woolen cord. On the obverse, the image relief is low; the reverse is plain. The head of the character is rounded; the hair is shown in the form of double plaits. The eyes are large and almond-shaped; the nose is broad and flat; the mouth is rendered with an ovoid depression. The neck is decorated with a double torque. The clothing is open-fronted, the neckline and shoulders are decorated with round "pearls". The lower portion of the chest indistinctly shows the folded arms.

9. Plaque $3.8 \times 2.9 \mathrm{~cm}$, ovoid in shape (Fig. 4). This is cast along the outline of the anthropomorphic half-length image. The plaque shows casting-defects: underfilling along the edges, holes in the middle portion; the framing pseudo-twisted cord is hardly visible at certain portions of the plaque's edge. The obverse bears an image of a bearded character, in low relief; his haircut is not shown. The beard is depicted in a stylized manner, with vertical incisions. The eyes are large and almond-shaped; the nose is broad and almost flat. The large mouth is shown with an arched depression. A thick torque is depicted on the neck. The clothing is rendered poorly because of the low-quality casting; yet it is obviously open-fronted, decorated with lines of "pearls" along the neckline and sleeves.

10. Plaque $2.6 \times 1.7 \mathrm{~cm}$ in size (Fig. 5,1 ). The image on the obverse is made in low relief, on the flat background. The back is plain and has a punched-out hole for attachment in the upper part. The rectangular casting appears to be an integral piece, not cut out of the round plaque; the more so, as the head-and-shoulders image is
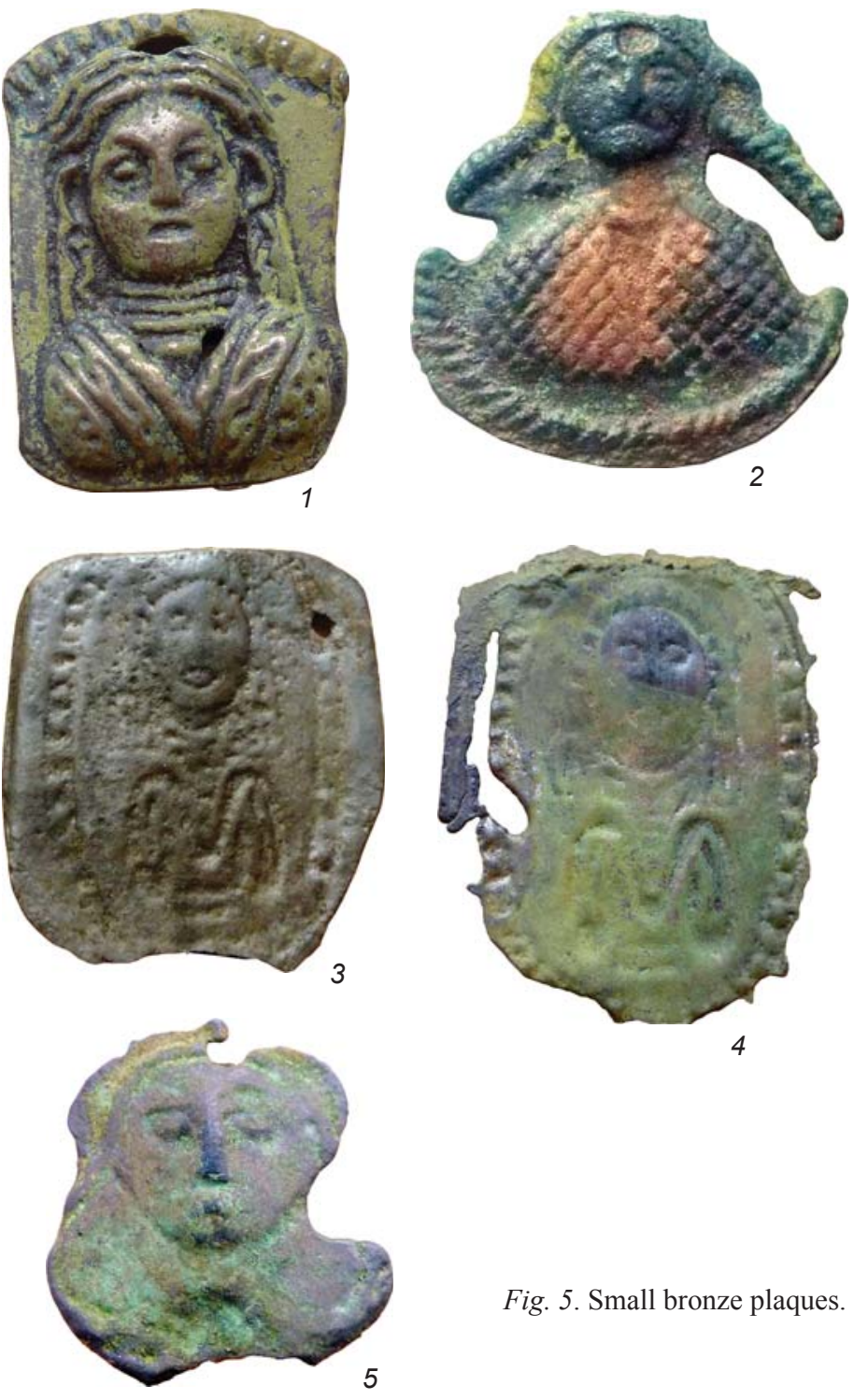

4

Fig. 5. Small bronze plaques. exactly inscribed into a rectangle. The upper edge is decorated with a fillet, imitating a line of "pearls". The character's face is rounded, the ears are protruding, the eyes are large and almond-shaped, the nose is broad and flat, and the mouth is shown with an oval depression. The hair is parted in the middle, and plaits reach the shoulders. An indistinct image of a torque consisting of four parts is depicted on the neck. The clothing is open-fronted; the collar is decorated with a line of duck-shaped depressions, the shoulders by round depressions.

11. Plaque $3.5 \times 3.6 \mathrm{~cm}$ in size, rounded in shape (Fig. 5, 2). This is a failed casting, with considerable underfillings. The plaque bears a head-and-shoulders image in low relief, the reverse is plain. The head of the character protrudes over the pseudo-twisted cord framing the plaque. There is a round depression on the forehead; possibly the artisan attempted to cast a hole. The head is rounded, the plaited hair melts into the cord. The eyes are large and almond-shaped; the nose is broad; the mouth

is rendered with an arched (with down-turned ends) depression. The neck shows something like a torque. The clothing is probably open-fronted, but owing to the lowquality casting the details are indiscernible. The clothing is completely covered with convex diamond motifs.

12. Plaque $3.8 \times 3.5 \mathrm{~cm}$ in size (Fig. 5,3 ). This is a failed casting. At the bottom, underfillings are recorded; at the top, to the left of the image, there is a hole. The plaque is subrectangular in shape, with rounded corners. The image is made in low relief, very indistinct in details. The long edges show an indistinct line of "pearls". The back is plain. The head of the anthropomorphic character is ovoid, the hairstyle is unclear and resembles plaits reaching the shoulders. The round eyes are poorly seen, the nose is hardly visible, the mouth is ovoid. The neck decorations are also indiscernible. The clothing looks like openfronted; the indistinct edging runs along the shoulders and sleeves, the ornamental motifs are hardly visible. 


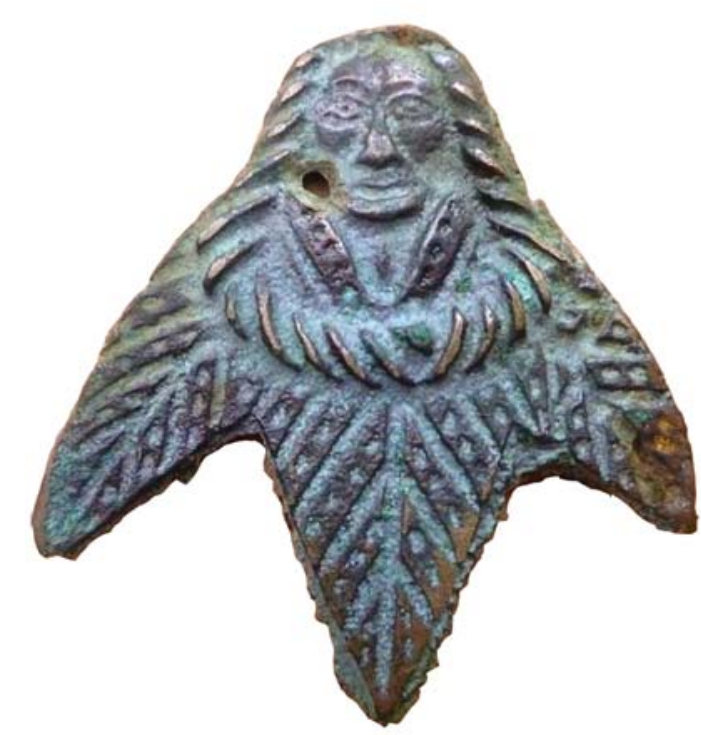

Fig. 6. Plaque in the form of a bird with anthropomorphic head.

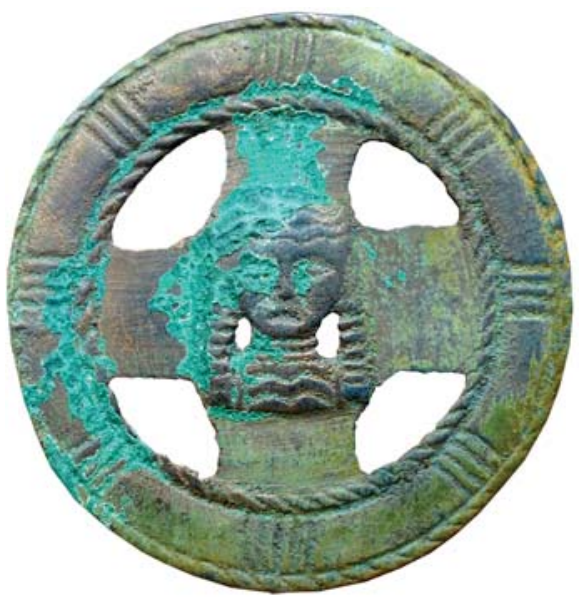

Fig. 7. Round, open-worked plaque in the form of a hoop and a cross-shaped figure.

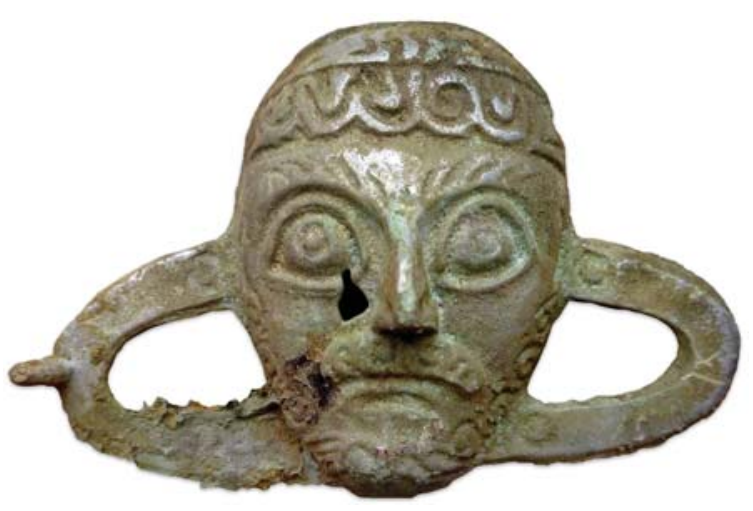

Fig. 8. Belt buckle (?).
13. Plaque $4.1 \times 3.1 \mathrm{~cm}$ in size (Fig. 5, 4). This is similar to the one described above, but the casting-quality is even worse. Under- and overfillings are noted at the sides. The edging shows an indistinct line of "pearls". The back is plain. The obverse shows a head-and-shoulders anthropomorphic image in the center. The head is ovoid; the hair is in the form of plaits reaching the shoulders. The eyes are round, the nose is not detailed, and the mouth is oval. The neck is decorated with something like a torque. The clothing seems to be open-fronted, with no clear ornamentation.

14. Plaque $3.2 \times 3.1 \mathrm{~cm}$ in size (Fig. 5, 5). This is a failed casting, underfillings are visible from all sides. The back is plain. The obverse shows a shoulder-high anthropomorphic image in low relief. The face is round, the eyes are almond-shaped, the nose is straight, the mouth is hardy visible. Details of clothing, hair, and adornments are not elaborated.

15. Plaque in the form of a bird with an anthropomorphic head (Fig. 6), $3.1 \times 3.1 \mathrm{~cm}$. The quality of casting is good; the casting-seams to show minor overfillings, suggesting that the plaque was not treated after casting. Near the right cheek-bone of the character, there is a hole drilled from both sides. The back is plain. The bird is shown with open wings; the wings and the tail are pointed. The head and upper part of the body have anthropomorphic features. The head is ovoid, the hair is in the form of stylized plaits turning into the chest adornment. The face shows prominent cheekbones, the arched eyebrows adjoin the broad nose, the eyes are almond-shaped, and the mouth rendered with an arched depression. Only the upper part of the character's open-fronted clothing is shown, which is decorated with round depressions along the collar. Lines of similar depressions decorate the wings and tail of the bird.

16. Round open-worked plaque $5.8 \mathrm{~cm}$ in diameter (Fig. 7). This consists of a hoop with an inscribed crossshaped figure. The reverse shows four semi-circular loops. The hoop is edged with pseudo-twisted cord; the space between the edges is decorated with groups of 3 to 5 convex lengths perpendicular to the edges. A headand-shoulders anthropomorphic character is shown in the center of the cross-shaped figure. The head of the character is rounded; the hair is shown in the form of stylized plaits. The eyes are almond-shaped; the nose is straight; the mouth is rendered with an arched (with down-turned ends) depression. The neck and chest of the character are provided with a stylized neck adornment and ornamentation of clothing.

17. A belt buckle (?), $4.2 \times 2.8 \mathrm{~cm}$, in the form of ovoid frame with a small hook at one side and with the head of an anthropomorphic character in the center (Fig. 8). The item was apparently not treated after casting; castingseams with metal overfillings are seen. The image is made in high relief. The head is ovoid, topped with a round 
cap; curly hair is shown. The large almond-shaped eyes are outlined with a double contour; the pupils are round. The eyebrows are depicted with short oblique lines. The nose is straight and prominent; the mouth is shown with a double arch. The mustache and beard are depicted with large curls, similar to those of the hair.

The cast items described above fall into two groups: round plaques of rather good quality (see Fig. 1, 8), and castings of various shapes and poor quality. The plaque in the form of a bird with the anthropomorphic head stands apart (see Fig. 6). Nevertheless, all the images demonstrate common iconographic features: the hairstyle in the form of plaits or curls, with temple decorations hanging to the shoulders; large, almond-shaped eyes; many images show prominent noses. The majority of the characters are depicted in open-fronted clothing, ornamented along the collar and shoulders.

The question arises of where, by whom, and based on which prototypes these bronze plaques were made. Let us describe a few similar artifacts. In northwestern Siberia, two silver plaques with head-and-shoulders images of a Parthian king were found: one of these was found in Khanty-Mansi Okrug, its exact provenance is unknown (it was acquired by the Khanty-Mansiysk Museum in 1939) (Kinzhalov, 1959); another (almost identical) plaque was found in the hoard near the village of Pikovka, in the Tomsk Region (it is kept in the Kolpashevo Local Museum) (Fedorova, 2018: 112, fig. 4, 6). The most accurate attribution of the Khanty-Mansyisk plaque was provided by E.V. Zeimal (Sokrovishcha Priobya, 1996: 4647). Recently, another silver medallion has become known, apparently cut off a dish with an image of a man, whose face and clothing are clearly of Parthian type (Fedorova, Gusev, Podosenova, 2016: 35). Actually, these examples, which served as prototypes for the above-described bronze plaques, are enough. It does not seem reasonable to discuss the features of the Parthian iconography reflected in sculptures, coins, etc., because these prototypes were not known to the population of Siberia.

According to Zeimal, "judging by iconographic details of the outfit and haircut, the silver medallion can be dated to the 80-30s of the 1st century BC (Sokrovishcha Priobya, 1996: 46). For us, it is no matter exactly what Parthian king was depicted on the medallion; what is important is the age estimate and iconography of the character. Notably, this iconography is quite similar to that of the bronze plaques under discussion: the pseudotwisted cord along the edges, representation of the haircut and short beard, large almond-shaped eyes, straight prominent nose, torque on the neck, and open-fronted clothing ornamented along the collar and shoulders. Evidently, real Parthian silver medallions served as prototypes for the discussed plaques.

The Kazym artifacts, unlike the Parthian medallions, were cast of bronze. Certain parallels can be provided: a head-and-shoulders anthropomorphic image from the sanctuary at Barsov Gorodok-1/9 (Shirin, Yakovlev, 2010: Ill. 59), a round "portrait" medallion supposedly from the same sanctuary (Ibid.: Ill. 72); a fragment of a plaque with a head-and-shoulders anthropomorphic image from an unknown archaeological site on the Tromyogan River (Ibid.: Ill. 98), and a round medallion from the cemetery near the village of Sogom, Khanty-Mansiysky District, KhMAO-Yugra (personal communication by A.V. Kenig).

The plaque 1 type occurs most frequently. Judging by the pictures provided at the treasure-hunting sites, four other similar items of various quality have been found beyond archaeological context: the first plaque was "from KhMAO-Yugra"; the second was found near the village of Sherkaly, Oktyabrsky District, KhMAO-Yugra; the third near Katravozh, Priuralsky District, YaNAO; and the fourth plaque was "from Trans-Urals". The only known parallel to plaque 2 is the item found in the village of Vagilskaya, Garinsky District, Sverdlovsk Region.

\section{Conclusions}

Thus, we can state, firstly, the abundance of "portrait" medallions, which became evident in the recent years; and secondly, their apparent replication, with variable castingquality (defective items have also been recorded). There can be two hypotheses. First, the castings, including those with visible defects, were produced beyond northwestern Siberia, and were imported here through trade links. However, it is doubtful that defective goods were bought anywhere in large quantities. The second hypothesis is more reasonable: high-quality imported goods made of precious metal (silver) were copied in northwestern Siberia or in Trans-Urals.

The latter hypothesis is supported by the following observations. First, as was mentioned above, the number of defect castings is significant. Second, images with similar iconography have been noted on the clearly local products, e.g., on the bird-shaped figurine (plaque 6). Third, numerous local copies of imported artifacts were recorded: ceramic vessels imitating bronze cauldrons on underpans; stone pendants imitating the pendants cut off the imported mirrors; ceramic beads imitating imported faience beads. Fourth, among the artifacts from the ritualmanufacturing center of Ust-Polui, a model made of clay slate was found, which apparently had been used as a template for a casting mold. The model shows the face of an anthropomorphic character of the "Parthian" type, similar to the images of a Parthian king on silver plaques from the Khanty-Mansiysk and Kolpashevo museums (Fedorova, 2018: 112, fig. 4, 7). Thus, it seems most probable that the Kazym "portrait" medallions were produced after the Parthian prototypes in northwestern 
Siberia. The dispersal area of these models, like many other imported goods, is the Lower Ob basin. To sum up, we should note that the presence of replicas of the imported goods testifies to stable cultural and trade links between northwestern Siberia and ancient centers of civilization.

\section{Acknowledgements}

Collection of facts, description, and analysis of artifacts 1-8 were carried out by A.V. Baulo under the Program XII.187.1 "Identification, Study, and Preservation of the Cultural Heritage of Siberia in the Information Society", Project No. 03292018-0007 "Study, Preservation and Museumification of the Archaeological and Ethno-Cultural Heritage of Siberia", state registration No. AAAA-A17-117040510259-9. Description and analysis of artifacts 9-17 and general attribution of the artifacts were carried out by N.V. Fedorova under the grant supported by the Russian Foundation for Basic Research, Project No. 1809-40011 "Urals and Western Siberia in the Archaeological Retrospective: Important Discoveries, Rhythms, Phenomena, and Paradoxes of Development".

\section{References}

\section{Baulo A.V. 2016}

"The old man of the sacred town": Ancient and recent representations of a bear-like deity from the Lower Ob, northwestern Siberia. Archaeology, Ethnology and Anthropology of Eurasia, vol. 44 (2): 103-113.

\section{Fedorova N.V. 2018}

Zapadnosibirskiye klady v kontekste istoricheskogo razvitiya territorii (ranniy zhelezniy vek-srednevekovye). In Trudy Kamskoy arkheologo-etnograficheskoy ekspeditsii Perm. Gos. Gum.-Ped. Univ., iss. XIV. Perm: pp. 88-113.

Fedorova N.V., Gusev A.V., Podosenova Y.A. 2016

Gornoknyazevskiy klad. Kaliningrad: ROST-DOAFK.

Kinzhalov R.V. 1959

Plastina s izobrazheniyem parfyanskogo tsarya. Sovetskaya arkheologiya, No. 2: 197-204.

Nezabitovska-Vishnevska B. 2017

Zerkala iz Gornoknyazevskogo klada (Yamalo-Nenetskiy avtonomniy okrug, Rossiya) - popytka interpretatsii. In I Mezhdunar. konf. "Arkheologiya Arktiki": Tezisy dokl. Yekaterinburg: Delovaya pressa, pp. 102-103.

Pristupa O.I., Starodumov D.O., Yakovlev Y.A. 2002

Okno v Beskonechnost: Bronzoviye zerkala rannego zheleznogo veka, Y.A. Yakovlev (ed.). Tomsk: GalaPress.

Shirin Y.V., Yakovlev Y.A. 2010

Martirolog yugorskoy arkheologii. In Khanty-Mansiyskiy avtonomniy okrug v zerkale proshlogo, iss. 8. Tomsk, KhantyMansiysk: Izd. Tom. Gos. Univ., pp. 21-62.

\section{Shulga P.I., Oborin Y.V. 2017}

Bronzoviye diski iz Kazymskogo klada i "vostochniye" zerkala-pogremushki. In Khanty-Mansiyskiy avtonomniy okrug $v$ zerkale proshlogo, iss. 15. Tomsk, Khanty-Mansiysk: Izd. Tom. Gos. Univ., pp. 84-23.

\section{Skripkin A.S. 1990}

Aziatskaya Sarmatiya. Saratov: Izd. Saratov. Gos. Univ. Sokrovishcha Priobya. 1996

St. Petersburg: Gos. Ermitazh.

Received February 18, 2019 